\title{
Automotive Milestones
}

\section{A Digest of the Opinions Expressed by the Leading Automobile Manufacturers}

\author{
As Reported by Austin C. Lescarboura
}

THEs automobile industry, after just passing through I a period of almost unbelievable prosperity, is now taking an inventory of itself-and of the future. New conditions have brought about new demands, which must be met if the industry is to forge ahead. Just what these conditions are and how the automotive industry purposes to meet them are matters of prime interest to automobile owner and non-owner alike; for the automobile of today is everybody's vehicle, playing a prominent rôle in the daily life of the entire community.

To begin with, automotive engineers are agreed that the passenger automobile has passed through its exIerimental stage and reached the period of comparative stability in performance and design. Great a:lvances will still be made in many details, but until somit new and revolutionary discovery or invention appears, new and revolutionary discovery or invention appears,
it is generally believed that we may expect these developments to be along the lines already laid down.

on the other hand, the passenger car is only begin ning to render to civilization the service which may confidently be expected of it within the next decade or two. Although there are already nearly eight million cars in use in America, the field of service ahead of us is almost limitless. The passenger car will, of us is almost limitless. The passenger car will,
within the next few years, bring about a vast relief in within the next few years, bring about a vast relief in
the congestion of our large cities by permitting people of all classes to live in the country and use their cars in going to and from work. The motor car will be increasingly used in making farm life tolerable and more profitable; it will give extended service along the lines it is already rendering to salesmen and men whose work takes them far and wide about the city and country; and it will come to be an indispensable servant of
the household as well as of the worker, so that we shall ind many families which are now content with one car, using two or three.

So much for these optimistic views concerning the future of the passenger car, which have proved to be quite representative of the entire automobile fraternity. But how about our roads? It has already been said that in certain sections of our country, particularly in the Far West, a further increase in the number of automobiles must await more and better roads. It is quite obvious that good roads must precede the increased use of automobiles. \section{The Highways and Byways of the}

The consensus of opinion among automotive authorities is that since transportation is one of the most vital essentials of our daily life, all good roads movements should not in any way be discouraged. The United States has not don so well in the matter of good roads as might be hoped for, considering our wealth and natural resources and volume of automobile traffic as compared with other nations. Still, the good roads question is receiving careful attention at the hands of State and Federal authorities alike. Big educational campaigns are under way with telling results. Some automotive experts strongly urge a close coöperation between Federal road action and a local action. They also urge better trunk lines, so to speak, over good roads passing east and west to both coasts, and north and south from central locations on the two borders. At least one automobile engineer comes forth with the suggestion that we are at a period when double-tracked roads must be given serious thought, in order to permit two-way traffic at higher speeds than at present and with less danger of accident.

of course, good roads mean everything to the automobile. Good roads mean more cars in use, better facilities to everyone in cities and rural districts alike, a lowering in the cost of living because of increased transportation facilities, and longer life and lower operating costs for all cars. Still, even automobile operating costs for all cars. Still, even automobile
enthusiasts, while advocating better roads, caution enthusiasts, while advocating better roads, caution
against the expenditure of extremely large sums of State and Federal moneys alike, at a time when tax ation is already a serious burden to business and in dividuals alike. Whatever moneys are available should be spent where they will do the most good.

And now we come to the matter of low-grade gasoline. Time was when gasoline could be bought at any gas station of such quality that it would rapidly evapo- rate if left standing in the open. But the heavy demands made upon the refiners have gradually lowered
the quality of gasoline used by motorists, necessitating certain provisions in the design of most en gines.

\section{Meeting the Lower Grades of Gasoline}

Automobile engineers have certainly faced the fue not only here to stay, but might become more acute as time goes on. Varied have been the ways to meet the fuel situation. For instance, the engineers of a leading automobile company invented a device known as the fuelizer, which was introduced in their car last spring. This device, by superheating a part of the flow of gas from the carburetor, insures almost perfect combustion of the fuel, making it possible to operate economically and efficiently any engine thus equipped, with the present lower grades of gasoline.

Other engineers have met the fuel problem through improvement in the design of the combustion chamber and intake manifold. Others are experimenting with exhaust heat with the idea of utilizing this heat to vaporize lower grade fuels, and in this way increase the overall fuel economy of their cars. Electric vaporizers are being installed in certain cars for the purpose of facilitating starting in cold weather, with present-day fuels. Still another idea which is being applied is to give each part of the intake manifold a special curve, so that gasoline does not collect in odd corners, get into the crankcase, and cause loss of power in general. Hot spots and vaporizing elbows are being introduced by other engineers. Certain it is that carburetor manufacturers have assisted in these problem unflinchingly, realizing that the problem was

would keep pace with the demand. Almost daily new sources of oil are being discovered, which, together line, should keep up the supply.

Still, it is best to be prepared, and ertain automobile engineers assure us that as soon as problems affecting the distribution of other fuels besides gasoline have been solved, it will be possible, with the knowledge already in hand, to devise engines which will be entirely satisfactory with almost any fuels.

There is no indication of any wide variation from the present standard designs of gasoline engines. The problems which have limited the use of steam and electricity seem as far from solution as ever, and while it is always possible that there will be some revolutionary discovery, there is no reason to expect one. The steam and electric types have had years in which to "make good," so to speak, and apparently have failed to compete successfully with gasoline cars except in a very small and limited way. Still, they may possibly gain ground in the near future, but if they do they will find the gasoline cars also gaining ground, since the perfection of the gasoline engine and the automobile in general is by no means realized today. All in all, we are assured that the gasoline automobile is here to stay-in our day, at least.

\section{A Word From Body Designers}

It is generally believed among the automobile fraternity that the bodies have reached the point where there should be few changes in design. There will, of course, always be freak bodies and undoubtedly occasional changes in design. But since the automobile sional changes in design. But since the automobile of a mere pleasure vehicle, there is no excuse for needless or faddish changes which seriously reduce the re-sale value of cars of previous models in the hands of buyers. As one body designer has put it, automobile lody design is a compromise between service, practicability and appearance; but above all the bodies must be useful and practical and sufficiently strong to give service and a certain amount of protec-

service
tion.

The closed bodies seem to become more and more popular. Indeed, with the constantly increasing change from touring cars with the top down to the steady use of these cars with the top up, certain designers believe that the next radical change in automobile bodies will be a change in automobile bodies will be a
touring car with a permanent top which mprovements in every way possible, for the good of he industry at large.

It appears that the engineers of the air-cooled type of car have been less affected by low-grade fuels than many other cars where the jacket loss is greater and where there is less heat efficiency inside the cylinders. 'This is due to the operating temperature of the aircooled car. Yet these engineers, not content with their initial advantage, have worked on a baffle-plate heater on the intake manifold to break up the heavier trifugal force against heated plates where the heat serves to break up much of the fuel which would otherwise be lost.

Truly, all these improvements have done much to increase the mileage of the present cars despite the lowered quality of the fuel. Many of the mediumweight cars are making better than twenty miles on a gallon, according to the claims of their designers. Starting in cold weather has been facilitated by some of the improvements mentioned.

Just what is ahead of us in the matter of fuel is difficult to determine. Several automotive engineers hasten to assure us that we have met the lowest grade fuels which will ever be utilized for automotive purposes, while others-a very small number, to be sureare equally emphatic in predicting kerosene, alcohol, that there is little to be gained in the use of still lower grades of fuel in passenger car engines. As was pointed out by the Secretary of the Petroleum Association in 1919, the demand for kerosene was such that there could not be much greater demand or the price would be equal to that of gasoline. It was the opinion of that authority that the supply of gasoline contents of present-day fuel by throwing them by cenand even crude oil. Still, the truth of the matter is will be somewhere between the present-day type of sedan and the so-called winter top bodies. At any
rate, the main object at present is to make the body as light as possible, consistent with safety and comfort of the passengers.

The matter of weight is an all-important one in present-day motoring, for the ever-increasing cost of fuel has to be compensated to some degree, and more efficient engine design cannot do it alone. Light weight is the better part of the solution. Hence one hears much about the many new alloys which are finding their way into automobile engines and other components. What is the status of this phase?

One engineer tells us that experiments are continually being made with new steel alloys and aluminum compounds; and there are indications that it will be possible shortly to reduce the weight of the cars to some extent. The application of these new materials, however, will be made in detail, and is not likely to be revolutionary at any one point. Still, manufacturers are using more alloy steel each year. Aluminum, on the other hand, is not being used to the extent of several years ago, by most builders. In fact, there is a strong block of automotive opinion which holds that aluminum is rather at a standstill than advancing as the metal for making parts for motor cars. Many engineers complain that it is too expensive. On the other hand, there plain that it is too expensive. On the other hand, there
are some who claim that aluminum is ideal. One engineer informs us that his company have been using considerable amounts of aluminum sheets and castings for some time, and are gradually increasing the use of this metal. So the engineering opinions as concerm aluminum are pretty much divided. For bodies, how. ever, aluminum appears to be considered with much (Continued on page 15) 
The Trend of Design for 1921 (Continued from page 5)

provided at the middle of the chassis, and contains a leather cup-packed piston, the space behind which is filled with oil. The piston is actuated by a short rod that extends to the brake pedal. Oil-distributing lines of flexible metallic tubing extend to the individual brake-cylinders on the rear wheels and also to corresponding members on the front wheels. It will be apparent that if pressure is applie!l to the brake pedal oil will be forced through the pipe lines to the four individual braking cylinders and the brake-band sectors will be spread apart with great force. It is stated that the hydraulic system eliminates practically all brake rods except that connecting the master plunger with the brake pedal.

The pressed steel frame has not changed in design for several years, with the exception that in most cars it has been made deeper at the center section, which has made it possible to dispense with running-board supporting-irons. On the sporting types of automobiles that are now so popular, the running boards are replaced with short steps no wider than the entrance doors. While the semi-elliptic spring still remains the most popular form for front suspension, a number of makers are adopting the simple quarter elliptic or cantilever spring for front suspension and the full cantilever spring for rear suspension. Disk wheels are being used in increasing numbers and they are apparently used on all varieties of cars in preference to wood or wire spoke forms wherever a real stylish design is desired. The metal disk wheels are strong and give the appearance of even greater strength and are much easier to keep clean than the spoke forms. They hide much of the car mechanism that is ordinarily exposed with the spoke form of wheel and give the impression of greater simplicity of chassis assembly.

Many refinements of detail are noticed in designs of bodies and especially in the interior finish and appointments of closed bodies. The sedan type is deservedly popular because it is an all-the-year form of car which provides maximum comfort for the passengers in either summer or winter and is best adapted for the rapidly changing weather conditions of the inter mediate seasons. In designing bodies of all types the builders have endeavored to secure seating arrangements that will provide inaximum comfort for the passengers. There has been no change in such standardized details as steering gears, change-speed, clutch and brake-control systems or the front-axle and steering knuckle construction because these have evidently been developed to a point of practical perfection beyond which it is difficult to go. A general tendency toward making lighter cars is noted and all the various refinements that make for more economical operation are incorporated in those cars designed by engineers who keep in touch with the public demand and who endeavor to cater to its needs.

\section{Automotive Milestones}

(Continued from page 6 )

favor, because it reduces weight most appreciably.

Aside from the use of special steels and aluminum, many engineers have found it possible to reduce weight by the simplification of certain parts and the elimination of non-essential parts. In some instances road shocks are being taken up by flexibility rather than by rigid construction, and this practice serves to keep the weight down consistent with road safety.

\section{The Matter of Tires}

Despite numerons attempts to replace the pneumatic tire, with its attendant troubles and high cost and limited life, it still holds the field. Its supremacy is absolute. Practically all automotive engi- neers are agreed that there is no reason to believe that a substitute for pneumatic res is in sight. And they are also greed that all substitutes so far brough to their attention during a period of fifteen years, are questionable. Automobile engineers have nothing but praise for the tire builders, who have steadily kept on mproving their product so that many of the former shortcomings of the pneumatic ire have been overcome, particularly in the cord tire. Some engineers believe that much can be done in the way of better pring suspension for taking some of the work off the present-day tires; but the majority seem to feel that the pneumatic tire is the logical means of taking up road hocks. The tire problem is solved to their satisfaction: if the motorist onl uses the proper sizes for his car and sees to it that they are kept inflated at the proper pressure, he should have little or no trouble.

Vibration has always been an inevitable feature of the gasoline automobile, especially at low speed. Still, just as noise has been steadily reduced until the present-day cars of the better kind purr along with no more fuss than the electrics, so re the engineers planning to reduce ibration. In the heavier engines vibration has already been reduced to a minimum, largely through the multiplying of lighter reciprocating parts and careful balancing.

Assuming that the motor is designed correctly with all parts well balanced and such parts as crank-shaft especially being sufficiently stiff, there still remains what is commonly known as torsional vibrations which occur at various speeds ing this vibration is successfully met however, by some makers through the mployment of a device attached to the rank-shaft. Some engineers are convinced that vibration can be diminisher to almost imperceptible proportions, bu others are not so sure of this. One engineer in particular directs our attention to the fact that there is little chance of eliminating any great amount of this ibration, except by the use of six-throw or multiples of six crank-shafts, since theoretically the four-throw crank-shafts used in four- and eight-cylinder engines cannot be balanced. Much is being done through the use of aluminum and composition pistons and connecting rods and other reciprocating parts. Vibration, for most engineers, continues to be more or ess of a problem which must be more or ess solved, according to the present status of their engines.

In conclusion, it is believed that the adances in automobile design in the next few years will be along the lines of still greater lightness and greater economy in at some sacrifice of power and speed acceleration. In Europe, however, there are now many cars on the market giving conomies of around 40 miles to the gallon of gasoline and develop 12 to 15 horse-power. It is probable that as fast as the demand for these light and cheap running cars appears in the United States, the American automotive industry will e able to meet it with engines having fewer disadvantases than the European types.

\section{Where Is That Rattle?}

(Continued from page 8 )

ioning the gear teeth and at the same time that prevents the gear case from vibrating ast enough to produce a musical, ather one should say unmusical, sound. A point in the transmission system that produces a rattling noise every time the clutch is engaged or the speed of the car varied suddenly by the accelerator is the universal joint. The reason that this produces noise is that the lost motion between the parts is taken up on the first application of power and the joint is rea(Continued on page 17)

\section{The Starting-Point for Low Prices}

Do you know what your machine operative can do to cheapen the cost of your product - by putting it through in less time? What he'll gain in speed you'll save in wages, when his "pep" and production is automatically checked-up by a

The large Set-Back Revis $1 / 2$ actual size. The small Revolution Coun er below is shown
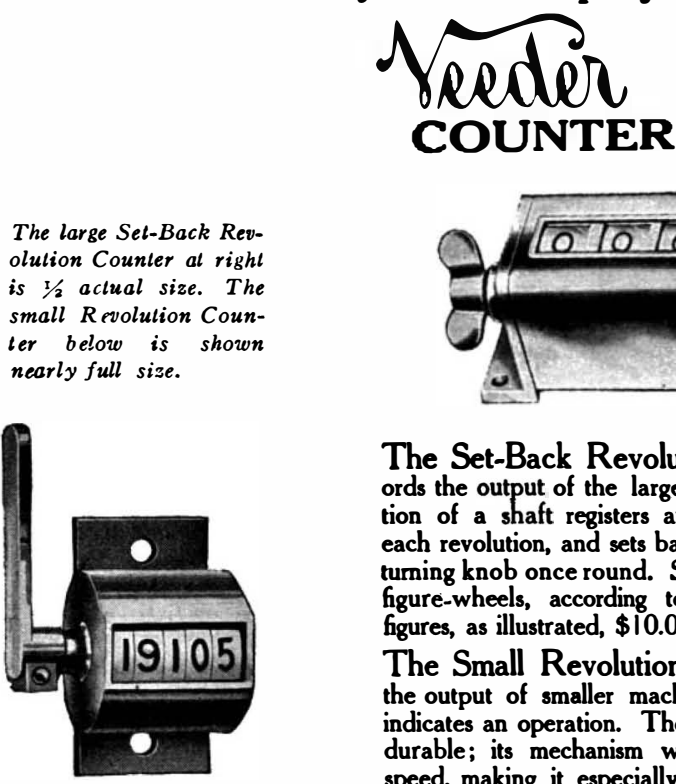

The Set-Back Revolution Counter above records the output of the larger machines where the revolution of a shaft registers an operation. Counts one for each revolution, and sets back to zero from any figure by turning knob once round. Supplied with from four to ten hgure-wheels, according to purpose. Price, with
fgures, as illustrated, $\$ 10.00$ (subject to discount).

The Small Revolution Counter at left records the output of smaller machines where a shaft-revolution indicates an operation. Though small, this counter is very durable; its mechanism will stand a very high rate of speed, making it especially adapted to light, fast-running
machines. Will subtract if run backward. Price, $\$ 2.00$.

Every machine where a reduced labor-cost is possible can have its Veeder counter. Let us send you the Veeder booklet; counters there for all purposes; see what it offers for yours.

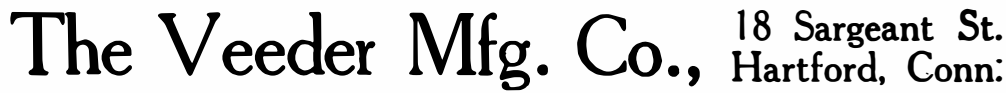

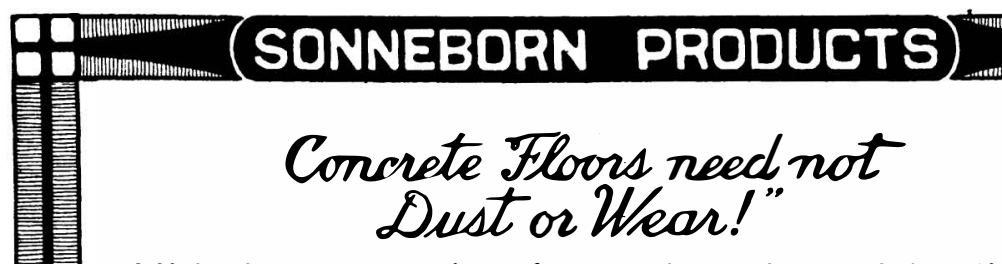

This is proven by the testimonials of leading plant owners and by the fact that $100,000,000$ square feet of concrete have been successfully treated with Lapidolith.

Textiles

"After using Lapidolith, we have no trouble with dusting, sanding or wearing away. We recommend Lapidolith to any who wish protection to concrete floors."

- Varsity Underwear Company,

\begin{tabular}{|c|c|}
\hline $\begin{array}{l}\text {-Varsity Underwear Company, } \\
\text { Balto., Md. }\end{array}$ & $\begin{array}{l}\text { Dort Motor Car Co. of } \\
\text { Flint, Mich. }\end{array}$ \\
\hline Steel & Foods \\
\hline
\end{tabular}

"Lapidolith has done all you claim for it. Others may well profit by our experience. We will

-Allegheny Steel Company of

"Lapidolith certainly hardens concretofloors, makes them easie to keep clean and makes the con-
crete last considerably longer." - Libby, McNeill \& Libby,

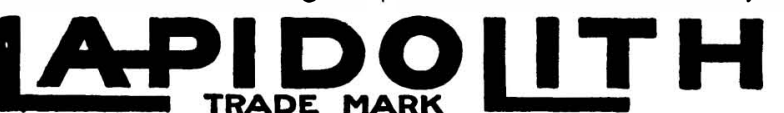

the original liquid chemical hardener makes concrete floors harder than granite, by completing the hydration of the cement.

There is a lapidolized floor near you. Let us refer you to it. Stop dust and disintegration-prevent repair costs-flush on Lapidolith.

Write for testimonials and literature.

L. SONNEBORN SONS, Inc.

Dept. 1 264 Pearl St., New York 